\title{
Design and Properties of Ni-TiN/SiC Nanocoatings Prepared by Pulse Current Electrodeposition
}

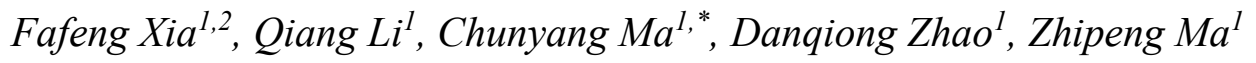 \\ ${ }^{1}$ College of Mechanical Science and Engineering, Northeast Petroleum University, Daqing 163318, \\ China; \\ ${ }^{2}$ College of Mechanical and Electrical Engineering, Hohai University, Changzhou, 213022, China \\ *E-mail: chunyangandma1@163.com
}

doi: $10.20964 / 2020.02 .15$

Received: 25 September 2019 / Accepted: 9 November 2019 / Published: 31 December 2019

\begin{abstract}
Ni-TiN/SiC nanocoatings were fabricated using pulse current electrodeposition (PCE) technique. The influence of plating parameters on morphology, microstructure, microhardness, and wear behavior of the resulting coatings were investigated by instrumental techniques such as transmission electron microscopy (TEM), scanning electron microscopy (SEM), X-ray diffraction (XRD) and X-ray photoelectron spectroscopy (XPS) as well as by tribological, abrasion and electrochemical testing. Test results confirmed incorporation of numerous $\mathrm{TiN}$ and $\mathrm{SiC}$ nanoparticles (with 45.9 and $37.2 \mathrm{~nm}$ average sizes, respectively) into the coating prepared at $4 \mathrm{~A} / \mathrm{dm}^{2}$ pulse current density. Cross-sectional views of this nanocoating revealed high concentrations of $\mathrm{Ti}$ (19.6 at\%), Si (12.1 at\%), and Ni (53.3 at\%). Microhardness of this $\mathrm{Ni}-\mathrm{TiN} / \mathrm{SiC}$ nanocoating was $848.1 \mathrm{Hv}$, which is significantly higher comparing to other coatings prepared in this work. The wear rate of Ni-TiN/SiC nanocoating prepared at $4 \mathrm{~A} / \mathrm{dm}^{2}$ was only $13.6 \mathrm{mg} / \mathrm{min}$, and only some small surface scratches were observed. Both of these results indicate outstanding wear resistance and performance of our novel $\mathrm{Ni}-\mathrm{TiN} / \mathrm{SiC}$ nanocoatings. In addition, Ni-TiN/SiC nanocoating deposited at $4 \mathrm{~A} / \mathrm{dm}^{2}$ had the smallest corrosion current density equal to $8.12 \times 10^{-6} \mathrm{~A} / \mathrm{cm}^{2}$, which indicates the best corrosion resistance.
\end{abstract}

Keywords: Ni-TiN/SiC nanocoating; pulse current electrodeposition; microstructure; microhardness; wear resistance

\section{$\underline{\text { FULL TEXT }}$}

(C) 2020 The Authors. Published by ESG (www.electrochemsci.org). This article is an open access article distributed under the terms and conditions of the Creative Commons Attribution license (http://creativecommons.org/licenses/by/4.0/). 